\title{
REVISTA
}

.
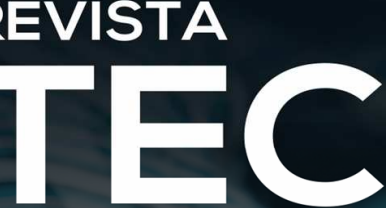

Edição Especial com publicação de trabalhos selecionados do V SIGEPRO

\section{PERCEPÇÃO DOS AGRICULTORES FAMILIARES SOBRE ERGONOMIA E SEGURANÇA EM TRATORES AGRÍCOLAS}

\author{
Aline Soares Pereira ${ }^{1}$, Ângelo Vieira dos Reis ${ }^{2}$, Mauro Fernando Ferreira ${ }^{2}$, Mário Conill Gomes $^{2}$, Elka Ojeda ${ }^{2}$ \\ ${ }^{1}$ CEng (Centro de Engenharias), UFPel, 96010-020, Pelotas, RS, Brasil. \\ 2 Programa de Pós-Graduação em Sistemas de Produção Agrícola Familiar, UFPel, 96010-900, Pelotas, RS, Brasil.
}

*E-mail: pereira.asp@gmail.com

\section{RESUMO}

O presente trabalho teve como objetivo analisar a percepção dos agricultores familiares sobre os temas ergonomia e segurança em tratores agrícolas. A escolha do tema para a realização deste trabalho foi baseada na importância de compreender como os agricultores entendem os conceitos, visto que estão diretamente envolvidos na seleção dos tratores no momento da aquisição do mesmo. Os tratores agrícolas são máquinas amplamente utilizadas nas propriedades rurais, portanto, os fabricantes devem seguir as recomendações normativas e de legislação para assegurar o conforto e segurança durante a sua operação. Para atingir os resultados propostos utilizouse um roteiro com algumas questões sobre ergonomia e segurança em tratores, este foi aplicado aos agricultores por meio de entrevistas. Após a análise dos dados, identificaram-se questões importantes a serem consideradas para construção de um sistema de avaliação de ergonomia e segurança para tratores novos utilizados na agricultura familiar. Entre essas questões destaca-se o entendimento do agricultor sobre o que é segurança, fundamentada em dois dispositivos previstos em normas, que são o cinto de segurança e o arco de proteção (EPC). E a definição sobre o termo conforto, que é percebida em tratores que possuem cabine, ar condicionado e assento com regulagens.

Palavras-chave: Agricultura familiar. Seleção de tratores. Pesquisa de campo.

\section{Introdução}

As transformações ocorridas nas últimas décadas nos sistemas de produção agrícola estão ligadas a investimentos realizados para melhorar a produtividade e a eficiência nas propriedades rurais. A mecanização exerce um papel fundamental nesse sentido. Por outro lado, se o planejamento da mecanização for feito de forma arbitrária e sem informação, os resultados negativos relativos a doenças ocupacionais poderão aparecer.

Programas de fomento à produção agrícola, como o Programa Nacional de Fortalecimento da Agricultura Familiar (PRONAF), estão colaborando com a transformação dos meios de

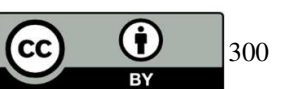




\section{REVISTA}

r

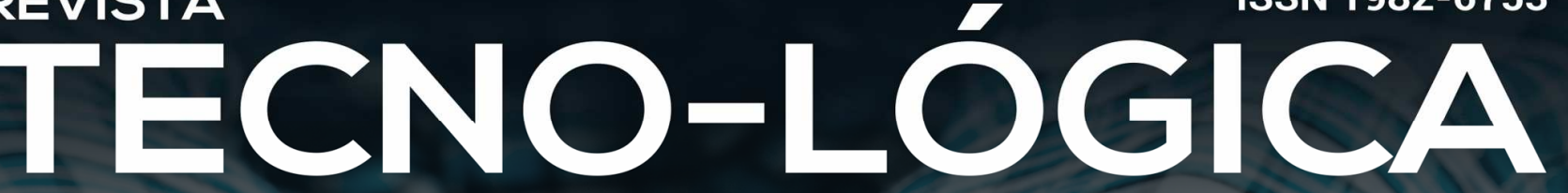

Edição Especial com publicação de trabalhos selecionados do V SIGEPRO

produção, pois atividades, antes realizadas manualmente, passaram a ser realizadas por máquinas como os tratores e implementos agrícolas.

De acordo com dados apresentados pela Associação Nacional dos Fabricantes de Veículos Automotores [1] no ano de 2019, de um total de 35.572 unidades fabricadas, o Brasil vendeu, internamente, no atacado, 33.148 unidades de tratores de rodas, dos quais 13.779 unidades com potência de até $58,8 \mathrm{~kW}$, que são aqueles elegíveis para aquisição com verbas do PRONAF. Com relação às regiões que mais venderam tais equipamentos agrícolas no mesmo ano, destacam-se a região Sudeste com 11.557 unidades e a região Sul com 11.364 unidades.

O Instituto Brasileiro de Geografia e Estatística (IBGE) divulgou, em 2019, o Censo Agropecuário com dados referentes ao total de tratores existentes nos 734.280 estabelecimentos agrários: 1.229.907 unidades. Ainda destacou que o investimento, nesses estabelecimentos advindos do PRONAF representou $76,6 \%$ dos recursos utilizados, principalmente para investimentos.

A mecanização acarreta em ganhos na produtividade e eficiência, os quais são fáceis de serem mensurados, por outro lado é necessário compreender que há aspectos relativos à qualidade de vida dos agricultores, no que se refere à saúde ocupacional. A esse respeito, Monteiro [2] alega que, no Brasil, estudos sobre acidentes rurais ainda são limitados, o que dificulta a avaliação das causas específicas do acidente e, também, restringe a base de dados que poderiam auxiliar no controle da frequência e gravidade dos acidentes. Além disso, em consonância com Machado et al. [3], apesar de muitas vezes ser necessária, a mecanização na agricultura traz muitos riscos à própria segurança do agricultor, o qual não é preparado para trabalhar apropriadamente com máquinas e implementos agrícolas. Autores realizaram um levantamento sobre os tipos de acidentes com tratores na Região Central do Rio Grande do Sul, ressaltando as principais causas desses, como por exemplo, desconhecimento de medidas de segurança, falta de atenção, dentre outros [4]. Ademais, identificaram que o capotamento do trator correspondeu a 51,7\% do total de acidentes graves na região [4].

É nesta perspectiva que estudos relativos à adequação de tratores às normas e legislações, bem como pesquisas sobre ergonomia e segurança, contribuem para melhorar a saúde dos agricultores.

O estudo apresentado neste artigo teve o objetivo de contribuir para a tese de Aline S. Pereira [5], que estabeleceu critérios para uma avaliação multicriterial de ergonomia e segurança para tratores novos utilizados na agricultura familiar, baseando-se na legislação, nas normas vigentes e no conhecimento de especialistas em máquinas agrícolas. A avaliação da percepção dos agricultores sobre os temas visou conhecer o assunto e os itens de avaliação que poderiam ou não ser incorporados nessa avaliação multicriterial. Os objetivos específicos se focaram em selecionar critérios para ser investigados através de uma entrevista aos agricultores; elaborar questionário de pesquisa; aplicar a pesquisa, avaliar e analisar os dados.

\section{Revisão Teórica}

\subsection{Abordagem da ergonomia e da segurança em tratores}

As transformações ocorridas, nas últimas décadas, nos sistemas de produção agrícola estão ligadas a investimentos realizados para melhorar a produtividade e a eficiência nas propriedades rurais. Nesse contexto, o trator agrícola é uma das invenções mais importantes de todos os tempos, uma máquina versátil, capaz de fornecer potência para executar os mais diversos trabalhos em uma propriedade rural.

A matéria publicada nesse periódico é licenciada sob forma de uma Licença Creative Commons - Atribuição 4.0 Internaciona http://creativecommons.org/licenses/by/4.0/

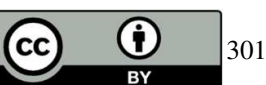




\section{REVISTA}

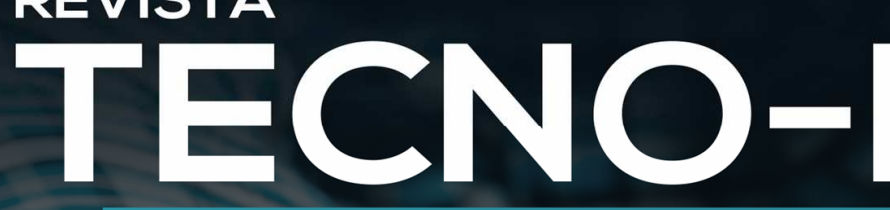

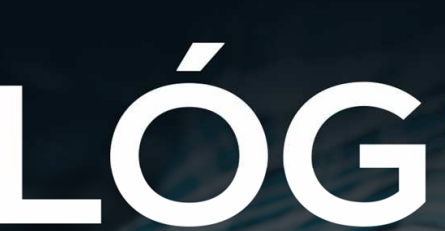

ISSN 1982-6753

Edição Especial com publicação de trabalhos selecionados do V SIGEPRO

A ergonomia é uma área de estudo que contribui para melhorar a qualidade de vida dos trabalhadores e os resultados operacionais, em termos de produtividade e eficiência. Iida esclarece que o princípio geral da ergonomia está baseado na premissa de que as máquinas e o ambiente de trabalho devem ser adaptados ao homem [6]. Sobre este fato, Filho e Naveiro [7] esclarecem que a ergonomia pode contribuir de forma decisiva para o sucesso do produto, na definição de características de interação entre o objeto e seus diferentes usuários. O correto dimensionamento de um produto deve considerar aspectos relativos às características físicas e cognitivas distintas para esses usuários. O uso dos princípios ergonômicos subsidia decisões e disponibiliza contribuições, de variadas formas, em diferentes etapas do projeto de um produto.

O uso de tratores agrícolas ergonomicamente mal projetados está relacionado com a ocorrência do desgaste físico e com inúmeros problemas de saúde comuns em operadores de máquinas agrícolas. Com essas consequências, é imprescindível mensurar as características antropométricas dos operadores e do seu trabalho, alcançando, desse modo, maior eficiência produtiva, maior grau de conforto, maior segurança na tarefa e obtenção de melhores condições de trabalho [8].

Autores comentam que as demandas em conforto e segurança para operadores de tratores agrícolas vêm tornando-se cada vez mais crescentes [9].

Os investimentos na mecanização trazem vários benefícios ao agricultor em termos de produtividade, mas, em contrapartida, podem causar uma série de problemas relacionados à saúde e à qualidade de vida. Nesse sentido, outros autores expõem que a introdução do trator agrícola como ferramenta de trabalho gerou um aumento considerável no índice de acidentes no meio rural, com consequências mais graves para operadores, ajudantes e terceiros [10].
Ambrosi e Maggi [11] realizaram um estudo, no interior do Paraná, sobre acidentes de trabalho relacionados às atividades agrícolas, identificaram 115 acidentes, sendo que $45 \%$ ocorreram com uso de máquinas agrícolas e tiveram, como principais causas, distração/brincadeira, excesso de confiança e ausência de equipamentos de proteção individual e coletivos. Uma pesquisa semelhante, realizada por Flores et al. [12], na zona da Mata Mineira, com operadores de máquina agrícolas, indicou que a principal forma de acidente é o capotamento lateral ou longitudinal do trator, chegando a $66 \%$ dos casos. Segundo os autores, os operadores relataram que os acidentes acontecem por falta de atenção e não por falta de capacitação desses operários. Machado et al. [3] apresentam alguns riscos durante a operação de tratores, como os dois tipos de capotamento: o lateral, que sucede quando o trator tomba para um dos lados, e o longitudinal, quando o trator tomba para trás em torno do seu eixo traseiro. Em ambos os casos, constituem-se em graves acidentes que podem ocorrer com trator e tratorista. Reis e Machado [13] relatam que, em um capotamento, as chances de sobrevivência do operador estão vinculadas à presença de uma Estrutura de Proteção na Capotagem (EPC) e ao uso concomitante do cinto de segurança. A estrutura constitui-se de uma sustentação metálica ligada diretamente ao chassi do trator, formando um ou dois arcos de proteção que delimitam uma região de proteção em torno do operador que, mesmo em um capotamento, são capazes de suportar os carregamentos estáticos e dinâmicos gerados pelo acidente. Baesso et al. comentam que grande parte dos acidentes envolvendo tratores poderia ser evitada se as máquinas envolvidas possuíssem dispositivos de segurança e se os operadores estivessem atentos ao uso dos equipamentos de proteção e às recomendações de segurança na execução das atividades [14].

A matéria publicada nesse periódico é licenciada sob forma de uma Licença Creative Commons - Atribuição 4.0 Internacional http://creativecommons.org/licenses/by/4.0/

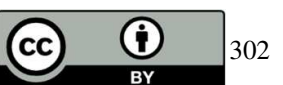




\section{REVISTA}

R

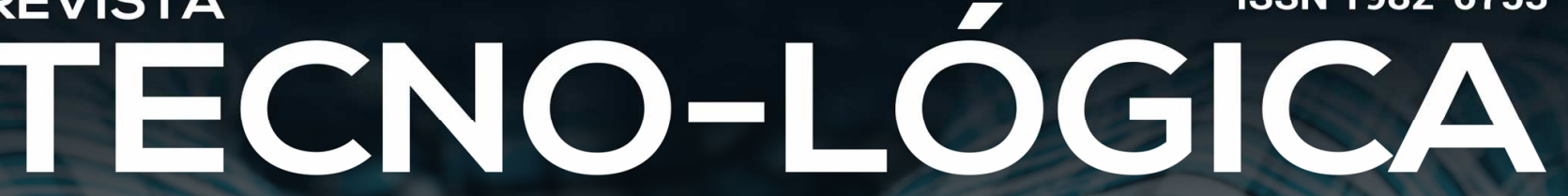

Edição Especial com publicação de trabalhos selecionados do V SIGEPRO

\section{Parte Experimental ou Metodologia}

A presente pesquisa é classificada como um levantamento, visto que se pretende investigar um comportamento que se deseja conhecer [15]. Nesse tipo de estudo, solicitam-se informações a um grupo de pessoas a respeito do tema proposto para, em seguida, mediante uma análise qualitativa, obterem-se as conclusões correspondentes aos dados coletados.

Sobre a coleta de dados com os agricultores, fizeram-se entrevistas estruturadas na Expoagro Afubra no mês de março de 2017. Essa feira tem uma programação técnica voltada para atender a agricultura familiar e ocorre há 17 anos na localidade de Rincão Del Rey, no município de Rio Pardo (RS). A abordagem dos agricultores ocorreu no estande do NIMEq (Núcleo de Inovação em Máquinas e Equipamentos Agrícolas) da UFPel (Universidade Federal de Pelotas), por meio de um roteiro estruturado com questões sobre ergonomia e segurança em tratores. Sendo essa uma pesquisa qualitativa, entrevistaram-se 15 indivíduos e os perfis dos entrevistados foram os mais diversos. Já as análises qualitativas foram realizadas a partir da metodologia de Ribeiro propõe a estruturação em três etapas: descrição, análise e interpretação dos dados [16].

\section{Resultados e discussões}

As respostas foram separadas em três blocos, o primeiro relativo ao perfil dos entrevistados, o segundo relativo às questões de segurança em tratores e o terceiro relativo a conforto. No caso de conforto, foi usado esse termo para delimitar o tema ergonomia, de forma a facilitar a compreensão do agricultor. As cidades de origem dos entrevistados foram as mais diversas: Dom Feliciano, Progresso, Venâncio Aires, Santa Cruz do Sul, Pelotas, Capela de Santana, Agudo, Barão do Triunfo, Segredo, todas do estado do
Rio Grande do Sul. As culturas mais comuns foram as de fumo, milho, feijão, arroz, soja, pêssego, forragem e figos. Sobre as marcas e modelos de tratores cita-se: John Deere 5055e, ano 2013, sem cabine; Massey Ferguson 275, ano 2010 (4x4); John Deere 5075e; Massey Ferguson 4275, 2010 com toldo; Massey Ferguson 4275; Trator Agrale 4100 4X2 e Massey Ferguson 265 ano 1986; Agrale 4230, ano 2013; Microtrator Yanmar TC 11 13,5 cv; Massey Ferguson, ano 2000; Massey Ferguson 265, ano 1986, Massey Ferguson 50x, ano 1974; New Holland TT 3840, ano 2017; Massey Ferguson 55x, ano 1973; Yanmar 1160, ano 2016; um dos entrevistados no momento não tinha trator. Em relação ao perfil dos entrevistados, a idade foi entre 25 e 60 anos, com exceção de um agricultor de 73 anos, todos do sexo masculino, a maioria com $1^{\circ}$ grau completo, experiência como tratorista superior a 6 anos, habilitados com carteira de motorista A, B, C ou D. A metade dos entrevistados têm capacitação sobre tratores, mas somente dois agricultores tiveram cursos com uma carga horária definida de $16 \mathrm{~h}$ de duração. Os demais consideraram capacitação como a entrega técnica do trator que geralmente é realizada pela revenda, após a aquisição da máquina. Nos cursos e nas entregas técnicas, os temas abordados são relativos às questões operacionais da máquina e ao uso do cinto de segurança. Os entrevistados com cursos formais fizeram sua capacitação no SENAR (Serviço Nacional de Aprendizagem Rural), os demais foram orientados pelos serviços de pós-venda das revendas de tratores.

Quando foi questionado ao agricultor sobre seu entendimento em relação à segurança em tratores, obtiveram-se as seguintes respostas: cinto de segurança, EPC (Estrutura de Proteção no Capotamento), estabilidade do trator, ter cabine, peso do trator, proteções, freios adequados, embreagem leve. Para questões voltadas ao comportamento adequado do operador e à capacitação, foram citados itens como cuidado na operação, regras

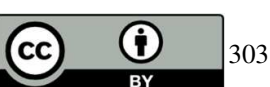




\section{REVISTA}

R

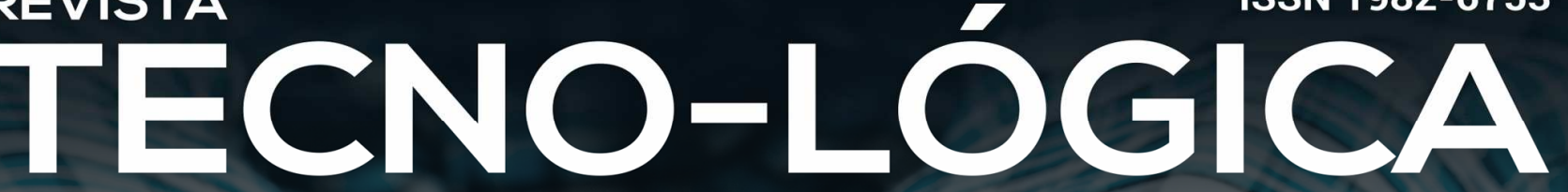

Edição Especial com publicação de trabalhos selecionados do V SIGEPRO

de uso (não dar carona), cuidados com os acessos, atenção e cuidado durante a operação e trabalhar de forma consciente para evitar acidentes. Na parte de capacitação, comentaram a importância de ter conhecimento sobre a máquina.

A respeito do segundo questionamento, sobre a aquisição de tratores mais seguros, metade dos entrevistados não consideraram a questão segurança na compra. Os que a consideraram, citaram os seguintes itens observados: possuir caixa de câmbio, que "impossibilita do trator sair andando sozinho"; ter cabine com arco de segurança (EPC), ter cinto de segurança. Referente à cabine, os agricultores relataram que o trator que tem esse elemento faz com que eles não se contaminem durante a aplicação de defensivos (nota-se aqui um claro desconhecimento que pode levar ao negligenciamento do uso de EPI, pois essa afirmação somente é verdadeira para cabines com sistema de filtragem de ar próprio para este fim). Outro item mencionado foi ter um acesso ao posto do operador adequado (escadas, corrimãos). Consideraram sistemas de câmbio em carga (troca de marcha no botão) como uma condição para melhorar a segurança, bem como ter potência no motor e sinais sonoros, além de um freio adequado e um conjunto hidráulico para facilitar o trabalho. Nesse mesmo sentido, foi perguntado para os agricultores se eles consideram seguro o trator que eles possuem e que riscos (perigos) eles oferecem. Os modelos de tratores mais novos, segundo eles, oferecem maior segurança e conforto; somente um agricultor, que possuí três tratores antigos, sendo um deles do ano de 1983 (< 30cv), um MF 265 de 1986 e um trator de rabiça da marca Tobata, relatou que esses exigem cuidados ao operar. À pergunta sobre quais proteções colocariam para evitar esses riscos, cinco agricultores citaram a cabine, o conjunto hidráulico e sinais sonoros, um dos entrevistados comentou que poderia se pensar em alguma proteção para a cabeça.
Outro tema pesquisado foi o contato desses agricultores com acidentes de tratoristas, em que a capotagem (fatal ou não) obteve maior índice, totalizando dez casos, alguns contados em detalhes, como a seguir.

Relato 1: "Capotagem com morte, o trator, no aclive, virou sobre o eixo e prensou o tratorista".

Relato 2: "Aconteceu com ele de subir na escada e se desequilibrar, o trator não estava com freio de mão puxado e quase passou por cima dele". Na outra vez, na tomada de potência, estava sem proteção e quase foi puxado, pois usava uma calça de abrigo que foi puxada ao invés dele. Outra vez, no modelo Valmet 185, deixou o trator no neutro e foi fazer uma regulagem, sendo quase atropelado. Esses acidentes ocorreram com o agricultor.

Relato 3: "Uma pessoa ia de carona na escada do trator. Ela se partiu e ele morreu esmagado. Outro perdeu a perna na tomada de potência". Esses acidentes não ocorreram com o agricultor.

Relato 4: "No trabalho, relato de um tratorista que caiu em uma ponte da propriedade e estava sem cinto, resultando em morte".

Relato 5: "Tombamento em aclive, o implemento pesou e o trator virou. Morte por esmagamento dos órgãos da barriga (fatal)".

Relato 6: "Capotagem por realizar manobras erradas. Comentou sobre um caso onde a carona no trator gerou quase um acidente com a perda do couro cabeludo". Esses acidentes não ocorreram com o agricultor.

Seguindo nessa linha, foi verificado sobre as possíveis causas geradoras desses acidentes e obtiveram-se as seguintes respostas: No aclive (segundo relato 1), o operador alegou ter descuido como tratorista. No relato 4 , o agricultor disse que a ponte onde ocorreu o acidente estava mal projetada. A falta de cuidado durante a operação foi outra causa citada. Com relação à máquina, o operador alega que ultrapassou os limites do equipamento durante a operação. E, referente à falta de capacitação, houve abuso da velocidade, imprudência e ousadia. 


\section{REVISTA}

ㄴ.

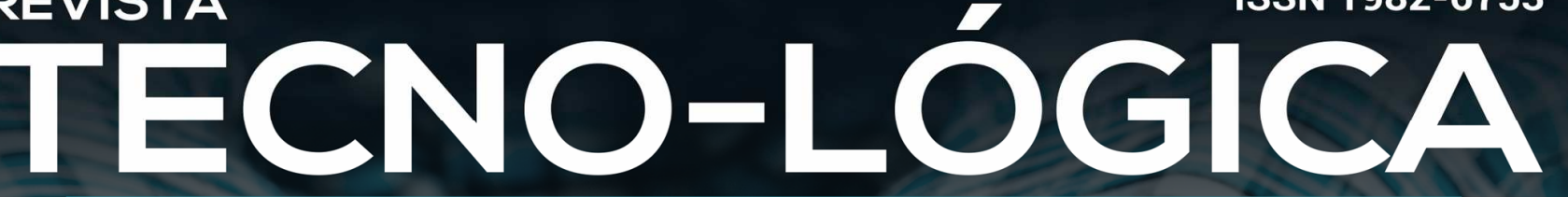

Edição Especial com publicação de trabalhos selecionados do V SIGEPRO

Também foram mencionados os aspectos que facilitam a dirigibilidade (operação) e quais dificultam. Entre os que facilitaram a operação, elencaram-se: marchas sincronizadas, direção hidráulica e com regulagem, sistema de frenagem, assento com regulagem, pedais adequados, painel de comando bem distribuído, sistema adequado de embreagem, tração, sistemas para facilitar a segurança, sistemas hidráulicos, caixa de câmbio "macia". Para os itens que dificultam, citaram-se: não haver marchas sincronizadas, patinagem no molhado, não ter direção hidráulica e tração dianteira e o comando do sistema hidráulico.

No terceiro bloco de respostas relativo a conforto (ergonomia), o entendimento do agricultor baseou-se nos seguintes itens: plataforma, localização do câmbio, caixa de marchas sincronizada. Nesse contexto, mencionaram as proteções de vidro na frente do posto do operador, assento confortável e com regulagem, a localização das marchas, toldo, cabine com ar condicionado, regulagens, molas no assento, potência do motor, "tudo próximo" (comandos, marchas), descanso para braços. À pergunta sobre considerar aspectos relativos ao conforto na aquisição, citaram-se: plataforma, câmbio do lado, caixa sincronizada, toldo, assento, ar condicionado, cabine, sistema hidráulico, freios e embreagem. Potência do motor, direção hidráulica, tração e freios não foram considerados, por quatro agricultores, na hora da aquisição.

Sobre considerar confortável o trator que possuem, os entrevistados relataram que sim, somente três responderam não por possuírem tratores antigos. Em relação a ter consequências negativas na sua saúde por operar tratores, os agricultores relataram: dor no pescoço (olhar pra trás para cuidar implemento), dor na coluna, dores nos joelhos (devido ao relevo e pedras na propriedade, que os obriga a usarem a musculatura das pernas para se equilibrarem), formigamento nas mãos, dores nas costas, dor nas pernas, ruído alto, dor na região lombar da coluna (encosto), dores na coluna, tendinites, dor nos braços e dores nos pés. Como recomendação para melhorar o conforto na operação de tratores, os agricultores sugeriram: melhorar a caixa de marchas, cabine para melhorar conforto ao trabalhar, regulagens no banco, trator ter cabine com ar condicionado (até mesmo devido à hora da aplicação dos defensivos), ter assento mais alto, bancada e hidráulica.

A seguir, três relatos que estavam fora das questões, mas que são significativos e serão descritos:

Relato 1: "Relato que a compra do trator é feita sempre para ganhar o vizinho, ele vê que se um tem um modelo do trator o outro quer ter melhor que o do vizinho. Ele pode se endividar, mas se vai ao galpão o trator está lá e eles trabalham feito loucos pra pagar o trator. Ele disse que o vizinho comprou trator e ele comprou um terreno na cidade e vai abrir agora uma padaria, vai largar a produção".

Relato 2: "Serviço de pós-venda é só para o grande, acima de 16ha".

Relato 3: "O câmbio sincronizado não é um opcional de conforto já que pouco deveria ser cambiado o trator durante a sua operação. Isso é um opcional muito exaltado pelos vendedores de trator".

\section{Conclusões}

A percepção dos pesquisadores sobre os agricultores é de que eles não consideram os requisitos de segurança e conforto em tratores. Os agricultores que apresentam idades acima de 50 anos, manifestaram maior resistência quando comparados aos mais jovens nas abordagens.

Entretanto, foi constatado que a escolaridade e a experiência de trabalho trazem maior conhecimento sobre esses aspectos. Também se observou que o entendimento sobre o que é segurança está alicerçado em dois itens que já fazem parte das

A matéria publicada nesse periódico é licenciada sob forma de uma Licença Creative Commons - Atribuição 4.0 Internaciona http://creativecommons.org/licenses/by/4.0/

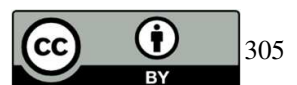




\section{REVISTA}

\section{r}

TEC CNO-

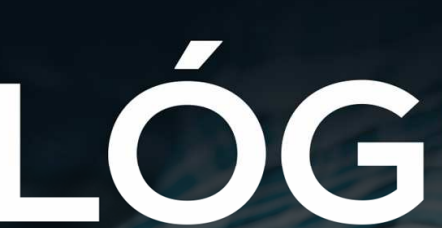
ISSN 1982-6753

Edição Especial com publicação de trabalhos selecionados do V SIGEPRO

normas e da exigência do mercado, que é o cinto de segurança e o arco de proteção (EPC).

$\mathrm{Na}$ parte da percepção de conforto, os itens mais comentados foram cabine, ar condicionado e assento com regulagens. Muitos vivenciaram acidentes com tratores, entre os mais comentados foram a capotagem e aqueles envolvendo a tomada de potência. Nesse sentido, a análise dos dados comprova realmente uma falta de conhecimentos específicos sobre os temas por parte dos agricultores para selecionar as máquinas mais adequadas para suas rotinas. Assim, é fundamental proporcionar um nível de confiança maior para que as aquisições dessas máquinas sejam realizadas, considerando não somente aspectos operacionais, mas também valorizando requisitos como conforto e segurança. Os requisitos apontam para um produto seguro e ergonômico, visando à proteção da saúde do trabalhador. Logo, estudos aplicados a essa temática são fundamentais para melhorar a qualidade de vida do "homem" e sua expectativa em relação ao trabalho.

Desse modo, entende-se que o presente trabalho contribuiu de forma indireta para a tese de Pereira (2019), visto que buscou investigar (para entender) como os agricultores familiares percebem os temas de ergonomia e segurança em tratores agrícolas. A partir da análise dos dados encontrados na pesquisa de campo, foi possível entender que é necessário investir na capacitação dos agricultores sobre os itens relevantes para seleção adequada dos tratores que vão ser adquiridos. Além disso, foi possível compreender o quão importante é aplicar um sistema avaliativo nos tratores de até $58,8 \mathrm{~kW}$, que seja capaz de identificar como estão os tratores agrícolas disponíveis no mercado frente à legislação, pois os agricultores desconhecem os fatores que podem prejudicar sua saúde durante a aquisição.

\section{Agradecimentos}

À Capes, pelo apoio financeiro para a realização desta pesquisa.

\section{FAMILY FARMERS' PERCEPTION OF}

\section{ERGONOMICS AND SAFETY IN AGRICULTURAL}

\section{TRACTORS}

\section{ABSTRACT}

This study aimed to analyze the comprehension of smallholder farmers on ergonomics and safety topics in agricultural tractors. The choice of the theme for carrying out this work is due to the importance of knowing how farmers understand the concepts, since they are directly involved in the selection of tractors at the time of acquisition. Agricultural tractors are machines widely used in rural properties; therefore, manufacturers must follow normative and legal recommendations to ensure comfort and safety during their operation. To achieve the proposed results we used a script with some questions about ergonomics and safety in tractors, this was applied to farmers through interviews. After analyzing the data, we identified important issues to be considered for establishing an ergonomics and safety assessment system for new tractors used in family farming. Among these issues, the farmer's understanding of what is safety is highlighted, based on two devices provided for in standards, which are the seat belt and the Roll Over Protective Structure (ROPS). And the definition of the term comfort, which is perceived in cab tractors, air conditioning and seat with adjustments.

Keywords: Family farming. Selection of tractors. Field research.

\section{Referências}

[1] ANFAVEA. Anuário da Indústria Automobilística Brasileira. Disponível em: <http://www.anfavea.com.br/anuario.html>. Acesso em: 20 abr. 2020. 


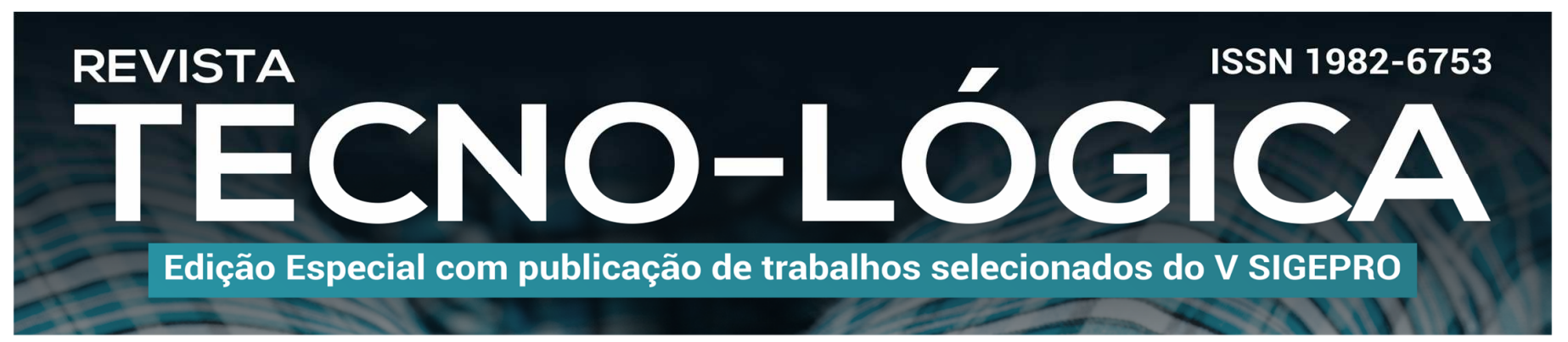

[2] MONTEIRO, Leonardo de Almeida (Org.). Prevenção de Acidentes com Tratores Agrícolas e Florestais. 1 ed. São Paulo: Diagrama, 2010. Online. Disponível em:

http://www.lima.ufc.br/arquivos_pdf/20140108105844.pdf>Acesso em: abr. 2015.

[3] MACHADO, Antônio Lilles Tavares; REIS, Ângelo Vieira dos; MACHADO, Roberto Lilles Tavares. Tratores para Agricultura Familiar: guia de referência. Pelotas: Ed. Universitária (UFPel), 2010. 123p.

[4] SCHLOSSER, José Fernando et al. Caracterização dos acidentes com tratores agrícolas. Ciência Rural, v. 32, n. 6, p. 977-981, 2002.

[5] PEREIRA, Aline Soares. Tratores para agricultura familiar: proposta de um modelo multicritério de avaliação considerando os requisitos de ergonomia e segurança. 2019. 386 f. Tese (Doutorado em Sistemas de Produção Agrícola Familiar) - Programa de Pós-Graduação em Sistemas de Produção Agrícola Familiar. Faculdade de Agronomia Eliseu Maciel. Universidade Federal de Pelotas, 2019. Disponível em: <http://guaiaca.ufpel.edu.br:8080/handle/prefix/4519>. Acesso em: 17 jul. 2019

[6] IIDA, Itiro. Ergonomia: projeto e produção. 2ed. São Paulo: Blucher, 2005. 630 p.

[7] FILHO, Eduardo Romeiro; NAVEIRO, Ricardo Manfredi. Ergonomia aplicada ao projeto de produto. In: FILHO, Romeiro (Org.). Projeto do produto. 1 ed. Rio de Janeiro: Elsevier-Campus, 2010. 171 a 192p.

[8] FONTANA, Gustavo; SILVA, Rouverson P. da; LOPES, Afonso; FURLANI, Carlos E. A. Avaliação de características ergonômicas no posto do operador em colhedoras combinadas. Engenharia Agrícola, v.24, n.3, p. 684-694, 2004.

[9] ROZIN, Dinorvan; SCHLOSSER, José Fernando; WERNER, Valmir; PERIN, Gismael F.; SANTOS, Paula M. dos. Conformidade dos comandos de operação de tratores agrícolas nacionais com a norma NBR ISO 4253. Revista Brasileira em Engenharia Agrícola Ambiental. [online]. 2010, vol.14, n.9, pp.1014-1019.

[10] FERNANDES, Haroldo Carlos; MADEIRA, Nildimar Gonçalves; TEIXEIRA, Mauri Martins; CECON, Paulo Roberto; LEITE, Daniel Mariano. Acidentes com Tratores 304 Agrícolas: Natureza, Causas e Consequências. Engenharia na agricultura. Viçosa - MG, v.22, n.4, p. 361-371, jul.-ago.2014.
[11] AMBROSI, João Nilson; MAGGI, Marcio Furlan. Acidentes de trabalho relacionados às atividades agrícolas. Acta Iguazu, Cascavel, v.2, n.1, p. 1-13. 2013.

[12] FLORES, Fábio Júnior Silveira; RINALDI, Paula Cristina Natalino; ALVARENGA, Cleyton Batista de; FERNANDES Haroldo Carlos; CIDRINI, Iorrano Andrade. Acidentes com tratores agrícolas em Rio Pomba, zona da mata de Minas Gerais. Revista Árvore, Viçosa-MG, v.27, n.6, p.887-895, 2015.

[13] REIS, Ângelo Vieira dos; MACHADO, Antônio Lilles Tavares. Acidentes com máquinas agrícolas: texto de referência para técnicos e extensionistas. Pelotas: Editora Universitária, 2009. 103p.

[14] BAESSO, Murilo Mesquita; MODOLO, Alcir José, BAESSO, Raquel Couto Evangelista, TROGELLO, E. Segurança no uso de máquinas agrícolas: avaliação de riscos de acidentes no trabalho rural. Brazilian Journal of Biosystems Engineering v. 12(1): 101-109, 2018.

[15] GIL, Antonio Carlos. Como elaborar projetos de pesquisa. 6. Rio de Janeiro Atlas $2017 \quad 1$ recurso online ISBN 9788597012934. Disponível em: https://pergamum.ufpel.edu.br/pergamum/biblioteca/. Acesso em: 19 mar. 2020.

[16] RIBEIRO, José Luis Duarte; Nodari, Christine Tessele. Tratamento de dados Qualitativos: Técnicas e Aplicações. Porto Alegre. FEENG/UFRGS. 2001. 